\title{
Support for the trophic theory of island biogeography across submarine banks in a predator-depleted large marine ecosystem
}

\author{
C. H. Stortini ${ }^{1, *}$, K. T. Frank ${ }^{1,2}$, W. C. Leggett ${ }^{1}$, N. L. Shackell ${ }^{2}$, D. G. Boyce ${ }^{3}$ \\ ${ }^{1}$ Department of Biology, Biosciences Complex, Queen's University, 116 Barrie St., Kingston, ON K7L 3N6, Canada \\ ${ }^{2}$ Fisheries and Oceans Canada, Bedford Institute of Oceanography, 1 Challenger Dr., Dartmouth, NS B2Y 4A2, Canada \\ ${ }^{3}$ Ocean Frontier Institute, Steele Ocean Sciences Building, Dalhousie University, 1355 Oxford St., PO Box 15000, Halifax, \\ NS B3H 4R2, Canada
}

\begin{abstract}
The trophic theory of island biogeography (TTIB) predicts that when predators are depleted, prey extinction rates decrease, leading to increases in prey alpha diversity and an increase in the slope of the species-area relationship (SAR). The TTIB has been tested and supported in a restricted set of systems at small spatial scales $\left(0.25 \mathrm{~m}^{3}\right.$ [reef patches] to $29500 \mathrm{~m}^{2}$ [terrestrial]). Across semi-insular fish communities on 10 offshore banks ranging in size from 534 to $10537 \mathrm{~km}^{2}$ on the Scotian Shelf (northwest Atlantic Ocean), we found support for the predictions of the TTIB. The prey SAR slope was significantly higher after the collapse of large predator populations than before the collapse, due largely to the immigration (or colonization) of many new prey species, principally on the largest banks. Coincident increases in core (resident) prey species densities, primarily on the largest banks, suggests that extinction risk decreased. The appearance of a strong SAR within the mesopredator trophic group in the post-predator collapse era $\left(\mathrm{r}^{2}=0.55\right.$ relative to 0.12 in the pre-collapse era) suggests that the TTIB may also apply to mesopredator release in insular marine communities. Increases in mesopredator densities coincident with the colonization of previously unoccupied banks by core mesopredator species suggests that range expansions contributed to the increased strength of the SAR. Our study contributes to our evolving understanding of island biogeography theory and suggests that TTIB may provide a useful framework for evaluating trophic alterations in large marine (and non-marine) ecosystems.
\end{abstract}

KEY WORDS: Alpha diversity · Marine $\cdot$ Fish · Predator-prey · Species-area relationship · Diversity $\cdot$ Trophic theory $\cdot$ Island biogeography $\cdot$ Mesopredator release

\section{INTRODUCTION}

The increase in alpha diversity (the number of species) with habitat area is considered one of the foundations of theoretical ecology (MacArthur \& Wilson 1967, Connor \& McCoy 1979). The classic equilibrium theory of island biogeography (ETIB) attributed this 'species-area relationship' (SAR) to the scaling of species immigration and extinction rates with habitat area and isolation (MacArthur \& Wilson 1967). Assuming that all species are equal, the immi-

*Corresponding author: christine.stortini@gmail.com gration rate increases with island area and decreases with isolation, while extinction rate decreases with island area and increases with isolation. It is becoming increasingly recognized that these rates, and subsequently the parameters of the SAR, vary with species interactions, such as predator-prey interactions, and species traits (body size, diet generality, and trophic group; Drakare et al. 2006, Ryberg \& Chase 2007, Holt 2009, Ryberg et al. 2012, Jacquet et al. 2017). The trophic theory of island biogeography (TTIB; Ryberg \& Chase 2007, Holt 2009, Ryberg et al.

(C) The authors 2018. Open Access under Creative Commons by Attribution Licence. Use, distribution and reproduction are unrestricted. Authors and original publication must be credited.

Publisher: Inter-Research · www.int-res.com 

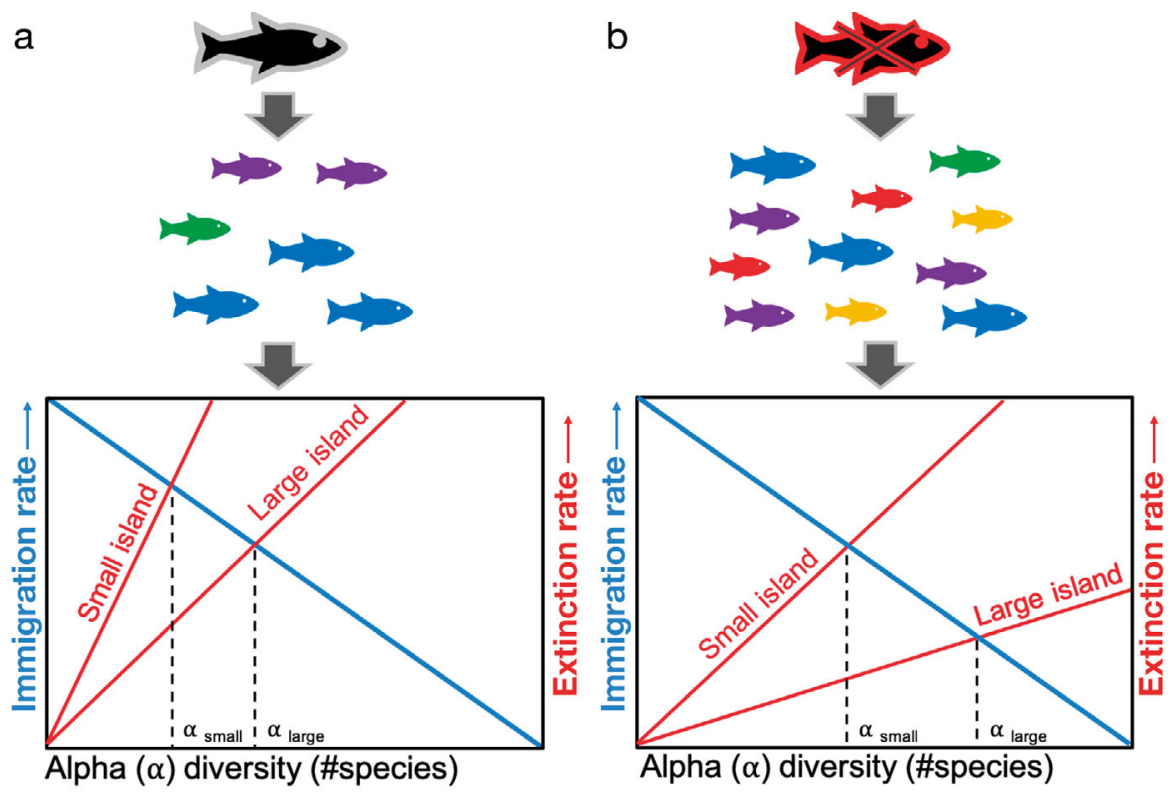

Fig. 1. Predictions of the trophic theory of island biogeography adapted to marine fish communities. (a) Assuming a constant immigration rate (blue line), the presence of large-bodied predators increases extinction rates (red lines) within prey communities, thereby reducing alpha diversity (number of different coloured fishes, and the point at which immigration and extinction rates intersect, as indicated by black, vertical dashed lines) of small-bodied prey on both small and large 'islands'; the small number of prey species overall leads to a smaller difference in alpha diversity between small $\left(\alpha_{\text {small }}\right)$ and large $\left(\alpha_{\text {large }}\right)$ islands (a smaller species-area relationship [SAR] slope). (b) When large-bodied predators are absent, prey extinction rates decline and alpha diversity increases, especially on large 'islands', leading to a greater difference in alpha diversity between small $\left(\alpha_{\text {small }}\right)$ and large $\left(\alpha_{\text {largel }}\right)$ islands, and therefore, an increase in SAR slope

2012) predicts that when large-bodied predators are depleted, the slope of prey community SARs should increase due to reductions in prey extinction rates (Fig. 1; Ryberg \& Chase 2007, Ryberg et al. 2012, Chase et al. 2009).

Since the publication of Ryberg \& Chase's (2007) TTIB, there have been only a small number of empirical tests of the theory, which have spanned a limited range of ecosystem types, and which occurred at small spatial scales. Ryberg \& Chase (2007) found that the absence of lizard and fish predators resulted in a significant increase in the slope of SARs of insect and zooplankton prey species in terrestrial glades ranging in size from $750-29500 \mathrm{~m}^{2}$ and in freshwater ponds ranging in size from $92-5834 \mathrm{~m}^{2}$. Stier et al. (2014) reported that reef patches (ranging from 0.25 to $0.5 \mathrm{~m}^{3}$ ) on which predatory groupers (Cephalopholis argus) were experimentally removed exhibited significantly higher alpha and beta diversities of the remaining fish species compared to reef patches with groupers. However, at this scale and small range of patch sizes, reef patch area did not influence the response. More recently, Johnston et al. (2016) reported that the presence of ciliate predators ( $\mathrm{Eu}$ plotes aediculatus and Stentor coeruleus) reduced prey (1 flagellate and 6 ciliate species) alpha diversity in a mesocosm meta-community of protists.
Macro-ecological studies conducted on the Scotian Shelf/Gulf of Maine region of the Northwest Atlantic Ocean, at scales ranging from $172000-300000 \mathrm{~km}^{2}$, have yielded initial insights into the response of fish communities to fishing-related perturbations. Here, a precipitous and prolonged collapse of large-bodied predatory fish populations occurred in the early 1990s as a consequence of overfishing (Choi et al. 2005, Frank et al. 2005, 2011). Shackell et al. (2012) reported that similarity among neighboring communities of 20 common large-bodied fish species progressively declined, concomitant with a reduction in average body size due to size-selective fishing. Subsequently, Ellingsen et al. (2015) found that as the regional occupancy of a dominant predator (Atlantic cod Gadus morhua) declined, both alpha and beta diversity of all remaining fish species increased. However, neither study evaluated the potential that trophic interactions or changes in the spatial scaling of diversity within trophic groups contributed to the community responses to the collapse of large-bodied predators. Moreover, in both cases, the regional fish community composition was characterized by a mixture of species occupying different habitats, and in the study by Shackell et al. (2012), the species considered represented only a small subset of the total species pool $(<20 \%)$. 
Here, we build upon these findings by testing the predictions of TTIB across 10 semi-insular (Frank \& Shackell 2001), highly productive, offshore banks on the Scotian Shelf in the northwest Atlantic Ocean. These banks were dominated by predatory groundfish species prior to their collapse in the early 1990s, which triggered an ecological regime shift (Frank et al. 2005, 2011). We tested the prediction that the slope of prey species SAR increased following the collapse of large-bodied predator populations on the banks. We also tested the hypothesis that the slope of mesopredator species SAR increased, as this group may have experienced a release from competition following large-bodied predator collapse ('mesopredator release'; e.g. Crooks \& Soulé 1999). Finally, we assessed temporal changes in bank community structure and trophic group-specific densities to evaluate the extent to which changes in alpha diversity were driven by expansion of core species and/or immigration of new species following the predator collapse.

Given the global nature of marine predator depletion (Worm et al. 2009, Juan-Jordá et al. 2011), body size reductions and consequent diminishing of predation efficiencies (Scharf et al. 2000, Shackell et al. 2010), species introductions (Bax et al. 2003, Cheung et al. 2009), and the likelihood of variation in community responses among ecosystems (e.g. keystone predation; Paine 1966), it is important that the predictions of TTIB continue to be tested at various scales and in a variety of ecosystem types. A greater understanding of how, why, and when classic ecological theories do, or do not, apply to various ecosystems will permit a broader understanding of the consequences of human disturbance. In turn, this will lead to improved management and restoration practices (e.g. Palmer et al. 1997).

It is widely understood that large predators are a necessary component of ecosystems, facilitating balance and stability, and keeping lower trophic levels in check. The development of the 'large fish indicator' as an indicator of ecosystem health (Shephard et al. 2011, Modica et al. 2014) is a testament to the global evolution of thought in this direction. However, current understanding of the biogeography of community responses to predator depletion, particularly at lower trophic levels, remains limited. By testing TTIB in a large marine ecosystem across semi-insular communities, we sought to uncover the role of habitat area in shaping marine fish community responses to predator depletion and place a stepping stone on the path toward a broader understanding of the processes underlying these community-level responses.

\section{MATERIALS AND METHODS}

\section{Offshore banks}

The offshore banks of the northwest Atlantic Ocean have been recognized as important and productive fishing grounds for centuries. In contrast, their ecological significance as 'underwater islands' has garnered less attention (but see Frank \& Shackell 2001). The offshore banks of the Scotian Shelf (<100 m depth, ranging in area from $534-10537 \mathrm{~km}^{2}$; Fig. 2) constitute the preferred summer habitat and principal nursery areas of many formerly dominant, and highly exploited, large-bodied predator species (Shackell \& Frank 2000, Ricard \& Shackell 2013). The maximum and average separation distance between these banks is 640 and $280 \mathrm{~km}$, respectively. Their average depth ranges from 60 to $90 \mathrm{~m}$, while the depth of surrounding waters averages $142 \mathrm{~m}$. Recirculation features (Loder et al. 1988, Cong et al. 1996) act to retain larval fish on these banks and thus contribute to population structuring at this scale (Frank 1992). This results in a high level of community insularity.

The dissimilarity between bank fish communities and adjacent deeper-water communities indicates that these banks function as discrete habitat 'islands'

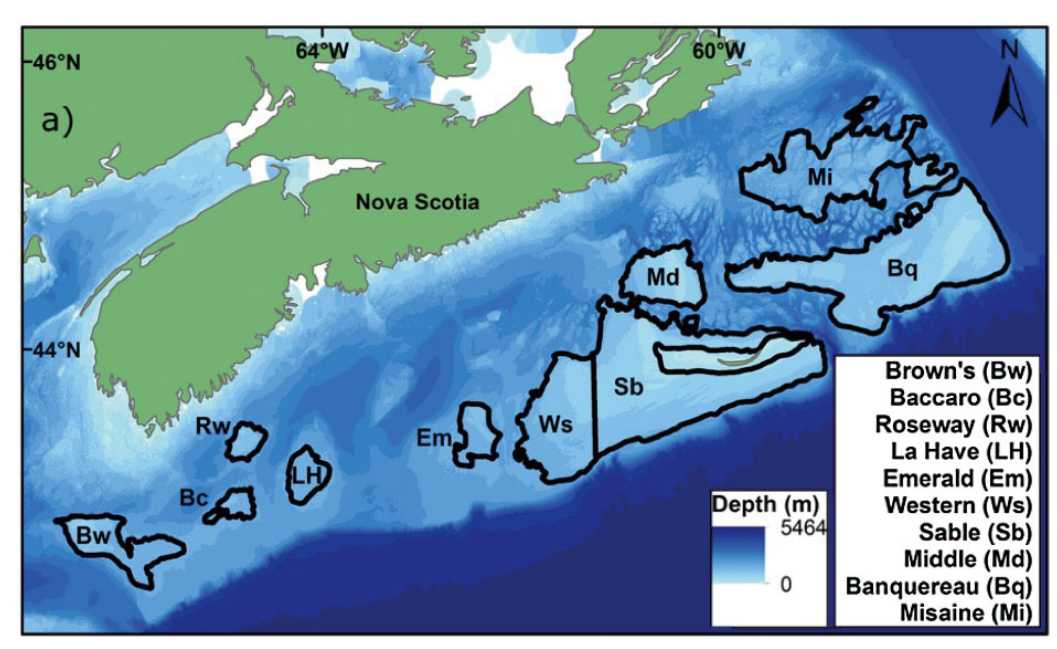

Fig. 2. Offshore banks of the Scotian Shelf. Topographical (depth) data were obtained from the Canadian Hydrological Service. Bank boundaries are defined by the $100 \mathrm{~m}$ isobath and have been routinely sampled by the Fisheries and Oceans Canada summer trawl survey (Fig. S2 in Supplement 1) 
bounded in ecological space (Supplement 1 at www. int-res.com/articles/suppl/m607p155_supp.pdf for all supplements). This concept is supported by the work of Frank \& Shackell (2001), who documented the existence of a strong $\left(r^{2}=0.81\right)$ SAR across the Scotian Shelf bank fish communities. In addition, they reported a strong positive correlation $\left(\mathrm{r}^{2}=0.58\right)$ between alpha diversity and population densities. Consistent with the predictions of ETIB (MacArthur \& Wilson 1967), this implied that the larger banks had lower extinction rates relative to smaller banks. Consequently, these banks would appear to be the ideal case study for testing the TTIB in a large marine ecosystem.

\section{Description of the data}

Records of species identity, presence/absence, abundance, and individual body lengths for the fish communities of each of the 10 offshore banks of the Scotian Shelf ecosystem (Fig. 2) were derived from scientific trawl surveys that span most of the benthic Scotian Shelf ecosystem and have been conducted annually during July since 1970 (DFO 2016). While some areas of the Shelf with very rugged topography and steep slopes have been less consistently sampled, the banks, which are characterized by relatively uniform depths, have been consistently and effectively sampled. Trawls were deployed at random locations within pre-determined sampling areas (strata) stratified by depth (Fig. S2 in Supplement 1). Standardized sampling methods ensured that annual effort was generally proportional to stratum area (for details see Doubleday \& Rivard 1981). In our alpha diversity estimations, only individuals identified to the species level were included (except for redfish, which constitutes 2 species that are not easily distinguished, i.e. Sebastes mentella and S. fasciatus). Due to variation in the distance trawled per sample, we multiplied each abundance and biomass record by the ratio of standard tow distance $(1.75 \mathrm{~km})$ to the actual distance towed. This standardized all abundance and biomass records to the standard sample area $\left(0.04 \mathrm{~km}^{2}\right)$, thereby limiting sampling bias in our temporal analyses.

The habitat of each bank was characterized using data collected during Fisheries and Oceans Canada (DFO) scientific trawl surveys and by the Canadian Hydrographic Service. The primary variable of interest, the area of each bank, was quantified using ArcMap 10.5 (ESRI), given the boundaries defined by depth in the design of DFO's July trawl survey strata (Fig. S2). Several secondary characteristics (Supplement 2) of the banks were evaluated as potential determinants of alpha diversity (see Supplement 6).

\section{Trophic groups}

In marine fishes, body size is generally proportional to trophic level (Romanuk et al. 2011). In northwest Atlantic temperate marine ecosystems, most dominant predatory groundfish species consume a wide range of prey items throughout the year, depending on availability and predator gape size (Link \& Almeida 2000). Due to gape size constraints, individual predators tend to eat prey items less than or equal to $50 \%$ of their body size (Scharf et al. 2000, Costa 2009). Given that each of the large-bodied predators had an average recorded maximum length per tow of $>60 \mathrm{~cm}$, their prey were conservatively defined as all species with an average maximum length per tow of $<31 \mathrm{~cm}$. By extension, species with an average maximum length per tow between 31 and $60 \mathrm{~cm}$ were defined as mesopredators. In only 1 case (Atlantic mackerel Scomber scombrus), body size did not reflect trophic level; this species was included in the prey trophic group (Supplement 3). Commercial mesopredators (haddock Melanogrammus aeglefinus, redfish [Sebastes spp.], American plaice Hippoglossoides platessoides, and cusk Brosme brosme; shown as commercial $\left[{ }^{\prime} \mathrm{C}^{\prime}\right]$ in Table S1) were removed from the analyses in order to limit bias related to the ongoing exploitation of these species. In effect, these mesopredators are predated upon by humans, and so their response to large predator depletion would likely be dampened. From this point onward, the mesopredator trophic group refers only to noncommercial mesopredators, i.e. those species that are not consistently commercially fished on the banks.

\section{Pre- and post-collapse regime definition}

At the scale of the entire Scotian shelf, Bundy et al. (2009) and Frank et al. (2011) reported an ecological regime shift, characterized by significant increases in the biomass of forage fish species and macroinvertebrates, in the early 1990s following the collapse of previously dominant predator species. Body sizes, condition, and population growth rates of large-bodied predatory fish declined across both western and eastern halves of the shelf and have yet to recover to their pre-collapse states 
(Shackell \& Frank 2007, Shackell et al. 2010), although some recovery of smaller-bodied, commercially exploited mesopredators has been evident (Frank et al. 2011). We confirmed that the temporal changes in the annual densities (average abundance per survey tow) of large-bodied predators, mesopredators, and prey at the scale of the banks were consistent with these shelf-wide dynamics (see Fig. 3). We were therefore able to explicitly define predator-dominant and predatordepleted time periods (i.e. pre- and post-collapse regimes) for our analyses. These analyses (completed using $\mathrm{R}$ version 3.4.3; R Core Team 2017) also quantified the population dynamics of prey and mesopredator populations in the pre- and post-collapse regimes.

\section{Slope of the SAR}

We tested the prediction, based on TTIB, that the collapse of large-bodied predators across the banks would induce a higher SAR slope for both prey and mesopredator trophic groups in the post-collapse regime relative to the pre-collapse regime. Due to the limited sampling effort on some smaller banks (e.g. 2 tows $\mathrm{yr}^{-1}$ on Baccaro and Roseway Banks), an analysis of annual SARs was not feasible. Alpha diversities of prey and mesopredator species were estimated for each bank in each regime (1970-1991 and 19922016) using the Jackknife 1 estimator in the 'vegan' package in R version 3.4.3 ('specpool();' Oksanen et al. 2017, R Core Team 2017). Several other alpha diversity estimators were compared (Supplement 4). The relative alpha diversities of the banks in both pre1992 and post-1991 regimes were consistent across estimators; the Jackknife 1 estimate was middle range and offered low associated error (Supplement 4). The Jackknife 1 estimator (Smith \& van Belle 1984) accumulates species richness across randomly selected tows and then adds an estimated number of species that were likely undetected. The estimated number of undetected species $\left(a_{1} \frac{(\mathrm{n}-1)}{\mathrm{n}}\right)$ is based on the number of species that were sampled only once during the selected period ( $a_{1}$, Eq. 1 below). Alpha diversity was estimated as the cumulative number of species (plus those undetected), as follows:

$$
S_{\mathrm{e}}=S_{\mathrm{o}}+\left\{a_{1} \frac{(\mathrm{n}-1)}{\mathrm{n}}\right\}
$$

where $S_{\mathrm{e}}$ is the estimated alpha diversity per cumulative number of survey tows (n), $S_{\mathrm{o}}$ is the number of species observed per $\mathrm{n}$, and $a_{1}$ is the number of spe- cies only observed in 1 of $\mathrm{n}$ tows. Total alpha diversity per bank, per regime, was calculated as the cumulative $S_{\mathrm{e}}$, when $\mathrm{n}=\mathrm{N}$ (total number of tows). The sampling variance associated with estimates of alpha diversity were calculated, according to Smith \& van Belle (1984), as:

$$
\operatorname{var}_{S_{\mathrm{e}}}=\left(\sum_{\mathrm{n}=1}^{\mathrm{N}} a_{1}^{2}-\frac{f_{1}}{\mathrm{~N}}\right) \frac{\mathrm{N}-1}{\mathrm{~N}}
$$

where $a_{1}$ is the number of species observed only once in $\mathrm{n}$ number of tows, and $f_{1}$ is the total number of species observed only once across all $\mathrm{N}$ tows.

The bank-specific Jackknife 1 alpha diversity estimates constituted the dependent variable for our derived SARs. A semi-log model (Gleason 1922) yielded the best fit to our data (largest $\mathrm{r}^{2}$ ) compared to alternative SAR model formulations, including Arrhenius, Lomolino, and Gitay (see Dengler 2009 for an overview). The regime-specific SARs took the following form:

$$
S_{\mathrm{e}}=k+z\left(\log _{10}(A)\right)
$$

where $S_{\mathrm{e}}$ is the Jackknife-estimated cumulative alpha diversity per bank, $k$ is the estimated intercept, $z$ is the slope, and $A$ is bank area measured in $\mathrm{km}^{2}$. A multivariate model with a bank area-regime interaction term was used to test for a significant change in SAR slope between regimes (ANCOVA). In both univariate and multivariate models, each $S_{\mathrm{e}}$ was weighted by the inverse of its corresponding variance $\left(1 / \mathrm{var}_{\mathrm{Se}}\right)$, such that alpha diversity estimates with larger error were weighted less heavily in the models. Both univariate and multivariate linear models were generated using the base package in $\mathrm{R}$ version 3.4.3 (R Core Team 2017).

The potential ability of other bank habitat characteristics (Supplement 2) to explain residual variability in alpha diversity was tested for using Akaike's information criterion corrected for small sample sizes (AICc; Mazerolle 2016) step-wise model selection, after accounting for collinearity among predictors using a sequential regression approach (Graham 2003, Dormann et al. 2013, Boyce et al. 2015; see Supplement 6). Sequential regression involves the regression of highly collinear predictor variables (e.g. predictor 1 and predictor 2), and the inclusion of residuals from this regression as a predictor in the model of alpha diversity, representing the residual effect of predictor 2 without double-counting the aspects of this variable that are collinear with the other, fully represented predictor 1 . Models were generated and assessed using R version 3.4.3 (R Core Team 2017). 


\section{Towards a mechanistic understanding of changes in SAR slope}

Central to the TTIB is the hypothesis that increases in the slope of prey SARs result from reduced extinction rates when predators are absent or depleted (Fig. 1). To gain insight into the potential mechanisms driving observed changes in prey and mesopredator SARs across the Scotian Shelf banks, we evaluated whether changes in alpha diversity were accompanied by changes in density (abundance per unit area). Extinction risk decreases as population sizes increase (Frank \& Brickman 2000, Dulvy et al. 2004, Hutchings \& Reynolds 2004), and larger habitats provide more area and a greater amount of resources to allow for population growth and maintenance (MacArthur \& Wilson 1967). Frank \& Shackell (2001) noted that the larger banks supported higher densities of fish in general, compared to smaller banks, implying that larger banks not only provided more area for population growth but also more resources per unit area. Therefore, if the slope of the prey (and/or mesopredator) species SAR increased in the wake of predator collapse, we would expect that prey (and/or mesopredator) density would also increase, particularly on large banks. For both prey and mesopredator groups, average abundance per tow was calculated per year (and per regime) on each bank and was evaluated in relation to the raw species counts per year (and alpha diversity estimates per regime).

Although the classic TTIB assumes a constant immigration rate, we explored the potential for increased immigration or successful colonization of prey and mesopredator species during the post-1991 regime. Trophic group compositions (including the frequency of tows in which each species was observed) were examined on each bank during each regime. Post-1991 appearances of species within prey and mesopredator groups that were not observed on individual banks in the pre-1992 regime were noted. Their pre-1992 frequency of observation on other banks, or off-bank areas, were also considered. These occurrences suggested potential migration or range expansion (suggesting reduced local extinction risk) of some species from other banks, and potential immigration or successful colonization of others from off-bank areas or other regions. Our assessment of changes in the correlation of bank community dissimilarities (using Bray-Curtis dissimilarity; 'vegan' package in R version 3.4.3; Oksanen et al. 2017, R Core Team 2017), with geographic distance between bank centroids, provided further insight into the origin of newly observed species. Dis- appearances of species from the banks in the post1991 era were also examined and contrasted to the appearances of new species.

\section{RESULTS}

\section{Pre- and post-collapse regime definition}

Our analyses revealed that annual abundance (standardized per tow) anomalies for the large-bodied predator trophic group were generally positive on all of the banks until the early 1990s. During this interval, $25 \%$ of the annual anomalies were, on average, $>1$ standard deviation (SD). Following this period, the predator abundance anomalies were generally negative with $26 \%$, on average, >1 SD (Fig. 3). Conversely, small-bodied prey species exhibited generally negative anomalies across all of the banks until the early 1990s and positive thereafter, with the frequency of annual anomalies $>1$ SD averaging $28 \%$ (Fig. 3). Negative prey anomalies were infrequent during the post-predator collapse regime, and, when they occurred, were always $<1$ SD. In both cases (predator and prey), the transition between negative and positive standardized anomalies occurred around 1991 ( \pm 3 yr) across all 10 banks (Fig. 3). We concluded that it is reasonable to consider the 1970-1991 period as a predator-dominated state (hereafter, 'pre1992') and the 1992-2016 period a predator-depleted state (hereafter, 'post-1991') across the banks.

Shifts in non-commercial mesopredator abundance were not as dramatic, but a small increase in abundance was evident across the majority of the banks in the post-1991 era, particularly on Brown's and Western Banks (Fig. 3). On average, a small proportion of mesopredator abundance anomalies (15\%) were $>1$ $\mathrm{SD}$ in the post-collapse regime; an even smaller proportion of anomalies were $<-1 \mathrm{SD}(9 \%)$. This differed from the more even dispersion of anomalies in the pre-1992 era (on average, $10 \%$ were $>1 \mathrm{SD}$, and $12 \%$ were <-1 SD).

\section{Slope of the SAR}

Prey species SARs were significant in both the pre$1992\left(\mathrm{r}^{2}=0.51 \mathrm{p}<0.05\right)$ and the post-1991 regime $\left(\mathrm{r}^{2}=0.83, \mathrm{p}<0.001\right)$, but were much stronger in the post-1991 regime (Table 1). Consistent with TTIB, the slope of the prey species SAR was significantly ( $p<0.05$ ) higher in the post-1991 era (Fig. 4a; refer to the significance of the area:regime interaction term 


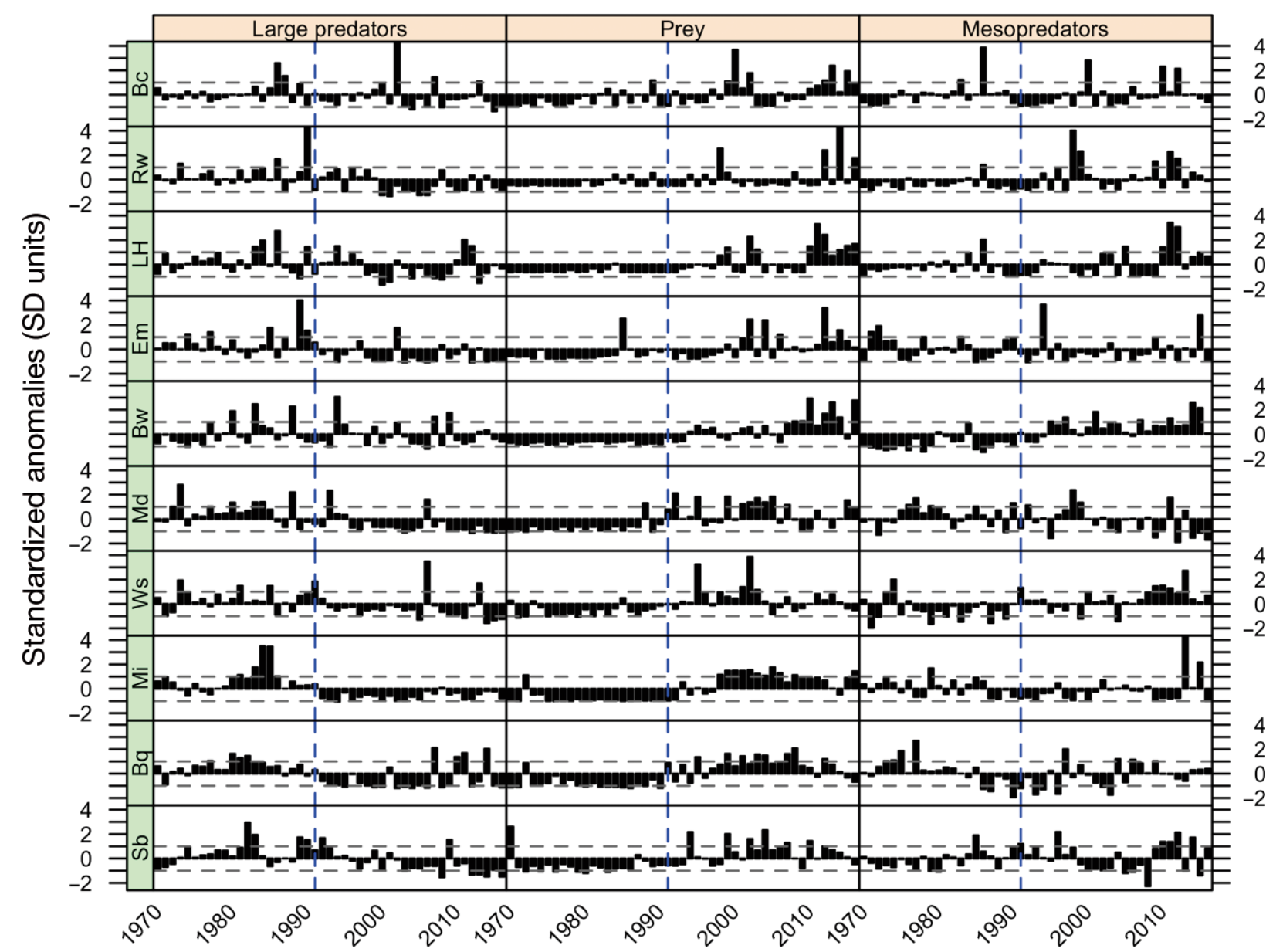

Fig. 3. Standardized annual density (abundance tow ${ }^{-1}$ ) anomalies (measured in standard deviations from the long-term mean, SD units) for large-bodied predators, prey, and mesopredators (trophic groups) on each of the 10 offshore banks arranged from the smallest (top) to largest (bottom): Baccaro (Bc), Roseway (Rw), La Have (LH), Emerald (Em), Brown's (Bw), Middle (Md), Western (Ws), Misaine (Mi), Banquereau (Bq), and Sable (Sb). Values were standardized and the anomaly was calculated according to $V^{s}{ }_{\mathrm{i}}=\left(V_{\mathrm{i}}-V_{\mathrm{Ave}}\right) / V_{\mathrm{SD}}$, where $V_{\mathrm{i}}$ represents the density in year $i$, the superscript $s$ represents the standardized anomaly, $V_{\text {Ave }}$ is the trophic group's long-term (1970-2016) average density on the bank, and $V_{\mathrm{SD}}$ is the associated standard deviation (SD). Grey horizontal lines mark \pm 1 SD. The blue vertical dotted line in each column marks the year 1991, separating pre-1992 and post-1991 regimes

in the ANCOVA model in Table 1). This was due to an approximate doubling of prey alpha diversity on 6 of the 10 banks: Brown's (Bw), Misaine (Mi), Banquereau (Bq), Middle (Md), Sable (Sb), and Western (Ws) banks, a response to large-bodied predator depletion (Frank et al. 2013). Through their interaction (in the multivariate model; ANCOVA), bank area and regime explained a significant proportion of variance in prey alpha diversity (adjusted $\mathrm{r}^{2}=0.80$, $\mathrm{p}<0.001$; Table 1). For both univariate (regimespecific) and multivariate (ANCOVA) models, assumptions of normality and homoscedasticity were upheld, and no sign of non-linearity was evident (Supplement 5). No other bank habitat characteristics contributed meaningfully to the limited residual variability in among-bank estimates of prey alpha diversity (Supplement 6).

The mesopredator SAR was not significant in the pre-collapse regime $\left(r^{2}=0.12, p=0.33\right)$, but was significant in the post-collapse regime $\left(\mathrm{r}^{2}=0.55, \mathrm{p}<\right.$ 0.05) (Table 1; Fig. 4b). This resulted largely from increases in alpha diversity on the largest banks ( $+38 \%$ on $\mathrm{Bq},+17 \%$ on $\mathrm{Bw}_{1}+63 \%$ on $\mathrm{Mi}$ ), decreases on 1 of the smallest banks ( $-37 \%$ on Rw), and limited changes in alpha diversity elsewhere. In the multivariate model (ANCOVA), the interaction of bank area and regime explained $28 \%$ (adjusted $\mathrm{r}^{2}$ ) of the variation in mesopredator alpha diversity $(p<0.05$; Table 1). This was due to a non-significant ( $p=0.245$; Table 1) increase in the slope of the mesopredator 
Table 1. Univariate, regime-specific species-area relationship (SAR) models and multivariate ANCOVA models for both prey and mesopredator trophic groups. Bank area was $\log _{10}$ transformed to obtain a linear fit; the semi-log model (Gleason 1922) performed best compared to all other alternative SAR models. In the ANCOVA models, the area:regime interaction term accounts for any changes in the effect of area on species accumulation (SAR slope) between regimes. The proportion of variance explained $\left(\mathrm{r}^{2}\right)$ and $\mathrm{p}$-values of each model are given, as are the parameter estimates and $p$-values for the individual predictors. The parameter estimate for area in the SAR models represents the slope $(z)$ of the relationship. The parameter estimate for the area:regime interaction term of the ANCOVA models represents the change in slope between regimes. The $p$-value associated with this estimate indicates whether the change in SAR slope between regimes was significantly $(\mathrm{p}<0.05)$ different from 0

\begin{tabular}{|c|c|c|c|c|c|}
\hline Trophic group/model & $\mathrm{r}^{2}$ & $\mathrm{p}$ & Predictor & Estimate & $\mathrm{p}$ \\
\hline \multicolumn{6}{|l|}{ Prey } \\
\hline \multirow[t]{2}{*}{ Pre-1992 SAR } & 0.51 & $<0.05$ & Intercept & -20.37 & 0.109 \\
\hline & & & $\log _{10}$ (area) & 9.78 & $<0.05$ \\
\hline \multirow[t]{2}{*}{ Post-1991 SAR } & 0.83 & $<0.001$ & Intercept & -47.10 & $<0.01$ \\
\hline & & & $\log _{10}$ (area) & 21.92 & $<0.001$ \\
\hline \multirow[t]{4}{*}{ ANCOVA } & 0.80 & $<0.001$ & Intercept & -45.84 & $<0.01$ \\
\hline & & & $\log _{10}($ area $)$ & 21.81 & $<0.001$ \\
\hline & & & Regime & 26.00 & 0.161 \\
\hline & & & $\log _{10}($ area):regime & 11.89 & $<0.05$ \\
\hline \multicolumn{6}{|l|}{ Mesopredator } \\
\hline \multirow[t]{2}{*}{ Pre-1992 SAR } & 0.12 & 0.33 & Intercept & 4.97 & 0.500 \\
\hline & & & $\log _{10}($ area $)$ & 2.15 & 0.331 \\
\hline \multirow[t]{2}{*}{ Post-1991 SAR } & 0.55 & $<0.05$ & Intercept & -4.88 & 0.410 \\
\hline & & & $\log _{10}($ area $)$ & 5.39 & $<0.05$ \\
\hline \multirow[t]{4}{*}{ ANCOVA } & 0.28 & $<0.05$ & Intercept & -4.88 & 0.411 \\
\hline & & & $\log _{10}$ (area) & 5.40 & $<0.01$ \\
\hline & & & Regime & 9.85 & 0.287 \\
\hline & & & $\log _{10}($ area):regime & 3.25 & 0.245 \\
\hline
\end{tabular}

SAR in the post-1991 regime, relative to the pre-1992 regime (refer to the interaction term in the ANCOVA model, Table 1), in which the slope was not significantly different from 0 (Fig. 4b; refer to pre-1992 estimate of area coefficient, i.e. SAR slope, and corresponding p-value, Table 1). Assumptions of normality and homoscedasticity were upheld (Supplement 5). No bank habitat characteristic, other than bank area, contributed meaningfully to explaining variability in the mesopredator alpha diversity (Supplement 6).

To evaluate the sensitivity of our results to our definition of the 2 regimes, we constructed prey and mesopredator SARs within 20 and $15 \mathrm{yr}$ moving windows (Supplement 7). We were then able to evaluate temporal trends in SAR slope (z) (Supplement 7). In general, we found that prey SARs from time periods constrained to the pre-1992 regime had significantly lower slope values than SARs from time periods strictly within the post-1991 regime. SAR slopes in time periods spanning both pre- and post-collapse regimes were intermediate (Supplement 7). With shorter (15 yr) windows, the transition period

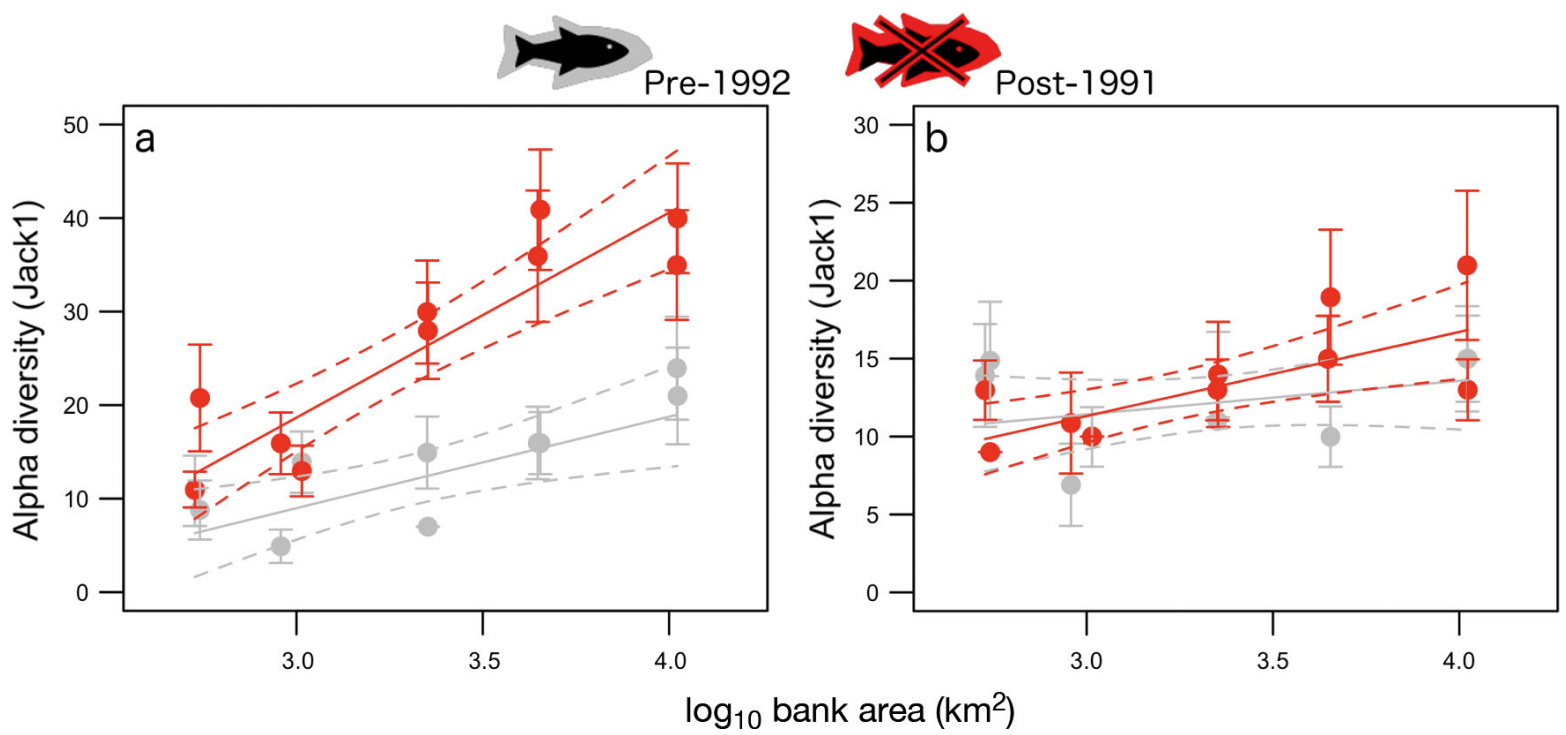

Fig. 4. Species-area relationships (SARs) for (a) prey and (b) mesopredators in the pre-collapse (grey) and post-collapse (red) regimes. Error bars represent $95 \%$ confidence intervals for each estimate of alpha diversity. The dashed lines surrounding the linear SAR trends (solid lines) represent the 95\% confidence intervals associated with the regime-specific SAR model fit 
Fig. 5. Relationship between pre1992 and post-1991 changes in (a) prey and (b) mesopredator alpha diversity and density (mean abundance tow ${ }^{-1}$ ). The blue solid line represents the fitted relationship (which was weighted by the product of the standard error of the differences in jackknife alpha diversity and density between regimes); blue dotted lines represent the error associated with the fitted relationship. Horizontal and vertical grey dotted lines indicate no change in either alpha diversity (horizontal) or density (vertical). Bank abbreviations as in Fig. 2

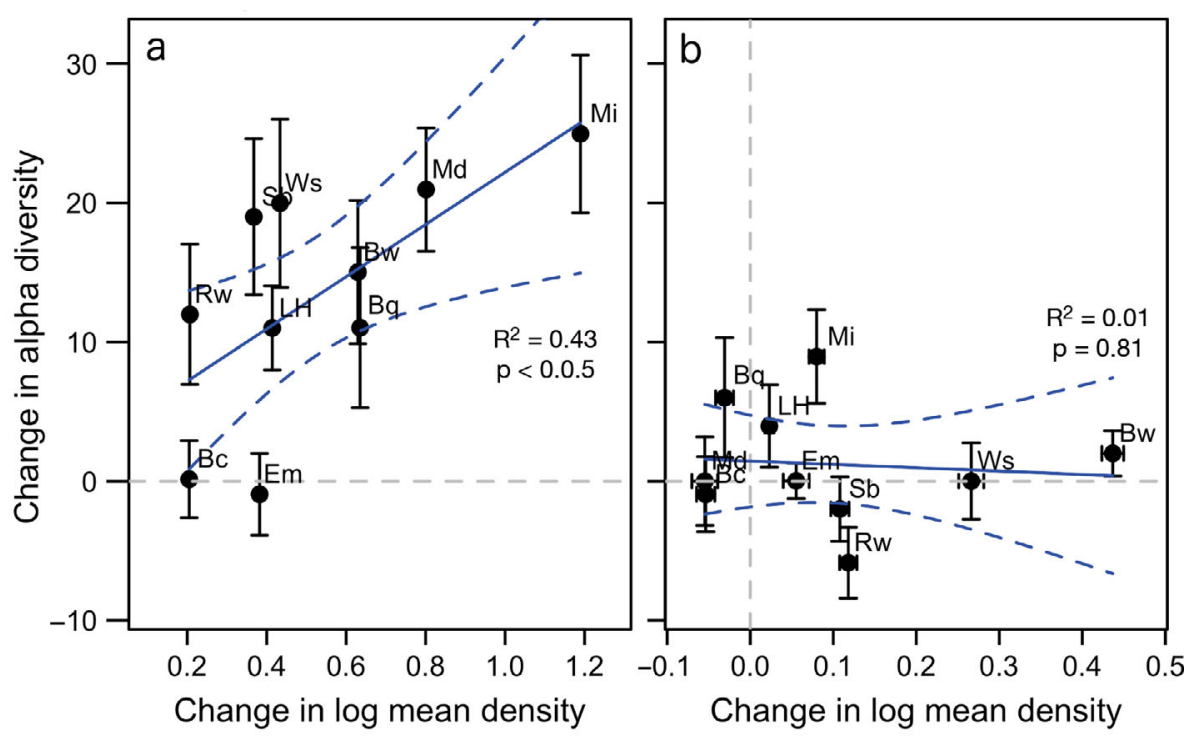

to post-collapse changes in alpha diversity were accompanied by changes in density (abundance per unit area) on each bank. Increases in prey alpha diversity across the banks were positively (and significantly) correlated with increases in prey densities, even when the relationship was weighted by the inverse of the product of standard errors associated with these changes $\left(r^{2}=0.43, p<0.05\right.$; Fig. 5a). An analysis of finer-scale temporal changes in prey densities and species counts (per year) revealed that positive trends in annual prey species counts were accompanied by, and strongly correlated with (average Pearson $r=0.46$, maximum $r=0.66$ on Misaine Bank), positive trends in annual prey densities on the majority of the banks (Supplement 8).

An analysis of species identities within the prey trophic group in each regime revealed that species
Fig. 6. Prey species richness in the (a) pre1992 and (b) post-1991 regimes. In the post1991 regime, all species previously unobserved on the banks were categorized as the 'Scotian Shelf (SS) pool' (those that were observed in deeper, off-bank regions of the Scotian Shelf in the pre-1992 regime), or 'colonist' (those that were not observed anywhere on the Scotian Shelf prior to 1991). 'Core' species constitute the prey species that were observed on the banks in the precollapse regime. On the $x$-axis, the 10 banks are arranged from the smallest (left) to largest (right). Bank abbreviations as in Fig. 2

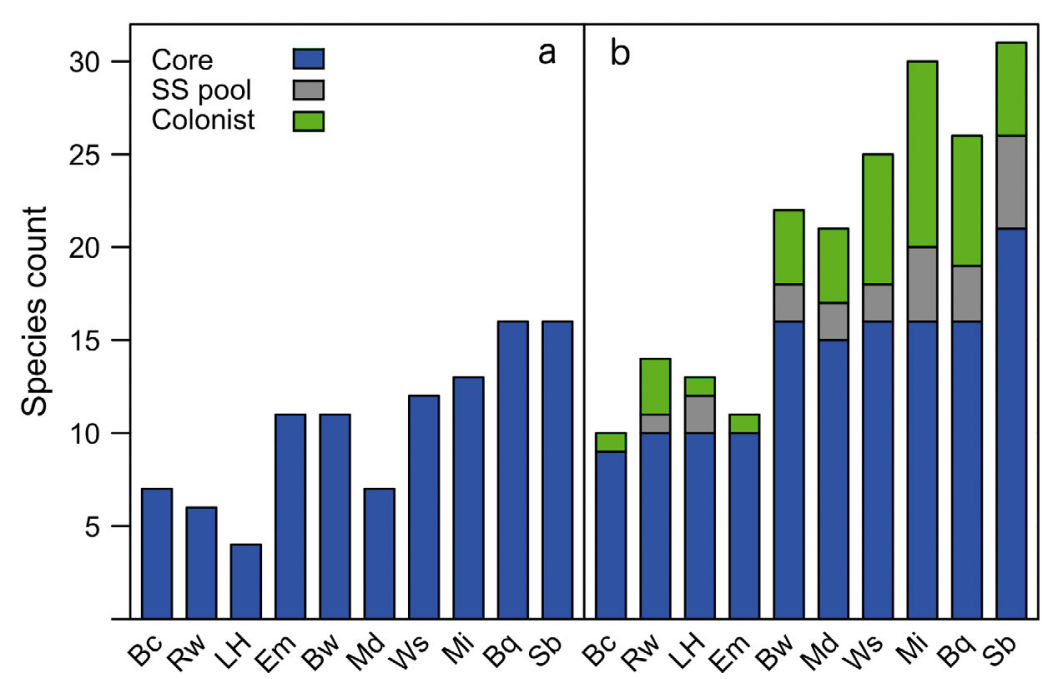


that were not observed anywhere on the Scotian Shelf prior to 1991 were largely responsible for the areadependent increase in prey alpha diversity in the post-1991 regime (referred to as 'colonists,' Fig. 6; Supplement 3). The colonists on the western half of the shelf were made up of species having southern affinities while the eastern half colonists were generally composed of species with northern affinities. Other contributing species to the post-1991 increases in alpha diversity originated from deeper habitats on the Scotian Shelf (referred to as 'SS pool,' Fig. 6; Supplement 3). One prey species (marlin-spike grenadier Nezumia bairdii), which was observed once on Western and Banquereau Banks in the pre-1992 era, became extirpated from the banks in the post-1991 regime (Table S2 in Supplement 3). This is in stark contrast to the 15 colonist and 11 SS pool species, which appeared on the banks in the post-1991 regime (Supplement 3).

Neither colonists nor SS pool species (together referred to as 'new species') contributed significantly to the observed increases in prey abundances across the banks (Supplement 9), and most new species were observed in only 1 to 4 tows per bank during the post-1991 period (Table S2). However, some colonists and SS pool species did become common in the post-1991 regime, being observed 17 (shorthorn sculpin Myoxocephalus scorpius) and 24 times (Atlantic hookear sculpin Artediellus atlanticus) on some banks. An increase in the strength of the correlation between community dissimilarity (given presence/absence of species) and geographic distance between banks in the post-1991 era $\left(\mathrm{r}^{2}=0.31, \mathrm{p}<\right.$ 0.001; Fig. $7 \mathrm{a})$ relative to the pre-1992 era $\left(\mathrm{r}^{2}=0.03\right.$, $\mathrm{p}=0.14$ ), suggested that the origin of colonist and SS pool species may have impacted post-1991 prey communities, and potentially the resulting SAR.

The development of a weak SAR in the mesopredator trophic group during the post-1991 regime, as contrasted to the non-existent SAR in the pre-collapse regime (Fig. 4b), is indicative of some level of release from competition following the predator collapse. There was no significant correlation $\left(\mathrm{r}^{2}=0.01\right.$, $\mathrm{p}=0.81$ ) between pre- and post-collapse changes in mesopredator alpha diversity and densities (Fig. 5b). However, strong positive correlations between annual mesopredator species counts and densities were observed on Brown's (Pearson $r=0.63$ ), Western ( $\mathrm{r}=$ 0.52), La Have $(r=0.75)$, and Roseway ( $r=0.55)$ Banks (Supplement 8). Mesopredator species counts and densities remained relatively stable over time across the remaining banks (Supplement 8), with the appearance of only 2 colonist and 2 SS pool mesopredators to the banks in the post1991 regime (Supplement 3). The appearance of these 4 new species (2 colonists and 2 SS pool) did not dramatically contrast the extirpation of 3 mesopredator species (common searobin Prionotus carolinus, Artic eelpout Lycodes reticulatus, and offshore hake Merluccius albidus) from the banks in the post-1991 regime (Supplement 3). However, while the extirpated species were observed only once or twice per bank in the pre-1992 era, 1 colonist mesopredator species, Newfoundland eelpout L. terraenovae, was observed 7 times on Misaine Bank in the post-1991 era (Table S3 in Supplement 3).

Further investigation of species frequency of occurrence revealed that many mesopredator species with high frequency of occurrence on some banks in the pre-1992 era, and even higher frequency of occurrence in the post-1991 era, appeared on other banks
Fig. 7. Correlation of (a) prey and (b) mesopredator bank community dissimilarities, given presence and absence of species, and geographic distance (m) between bank centroids during pre-1992 (left column) and post-1991 (right column) regimes 
where they were previously unobserved in the post1991 regime, reminiscent of a range expansion (e.g. winter skate Leucoraja ocellata, witch flounder Glyptocephalus cynoglossus, yellowtail flounder Limanda ferruginea, little skate Leucoraja erinacea, monkfish Lophius americanus, and sea raven Hemitripterus americanus; Table S3). An increase in the strength of the correlation between bank mesopredator community dissimilarities and geographic distance among banks in the post-1991 regime $\left(\mathrm{r}^{2}=0.22, \mathrm{p}<0.001\right)$ relative to the pre-1992 regime $\left(r^{2}=0.002, p=0.67\right)$ (Fig. 7) suggests that movement of mesopredator species among banks, or from similar off-bank areas, contributed to changes in bank mesopredator community compositions, and potentially the mesopredator SAR, in the post-1991 regime.

\section{DISCUSSION}

Our results provide support for the predictions of TTIB across the perturbed submarine banks of the Scotian Shelf. To our knowledge, this is the first study to find support for TTIB at large spatial scales, in a marine ecosystem, and for any ecosystem at these scales. Alpha diversity of prey species increased on the banks in the post-predator collapse regime (post1991), the increase being greatest on the largest banks. The result was a significant increase in the slope of the SAR for this trophic group (Fig. 4a, Table 1). Based on TTIB, we also anticipated that the collapse of large-bodied predator populations would result in increased alpha diversity and the slopes of SAR within the mesopredator complex.

A substantial body of literature details the phenomenon of 'mesopredator release,' i.e. release from competition and/or predation on juvenile stages, associated with the depletion of large-bodied predators (Crooks \& Soulé 1999, Baum \& Worm 2009, Prugh et al. 2009). A nearly non-existent SAR during the pre-1992 period resulted in a lack of statistical significance in terms of the increase in SAR slope for the mesopredator trophic group in the post-1991 era. However, the strength $\left(\mathrm{r}^{2}\right)$ of the relationship more than quadrupled (Fig. 4b, Table 1), and bank area was the only significant predictor of alpha diversity within this trophic group, as it was for the prey trophic group (Supplement 6). We interpret this finding as support for the hypothesis that TTIB may also apply to mesopredator release in marine ecosystems.

The finding that increases in prey SAR slope were coincident with reduced extinction rates in core prey and mesopredator species when predators were de- pleted further supported the mechanistic underpinnings of TTIB. Numerous investigations (e.g. Frank \& Brickman 2000, Dulvy et al. 2004) have noted the strong positive correlation between population size and extinction risk. Other determinants of extinction risk include geographic range size, habitat alteration, responses to exploitation, and life history traits such as age at maturity, body size, life span, and growth rate (Hutchings \& Reynolds 2004). An examination of all potential indicators of extinction risk was beyond the scope of this paper. However, the increased densities of core prey and mesopredator species (both smaller-bodied and therefore inherently at lower risk of extinction than large predators; Reynolds et al. 2005, Olden et al. 2007) in the post-1991 era, suggests that extinction risk was diminished. Moreover, in the post-1991 era, many mesopredator species exhibited increases in their frequency of occurrence on the banks and an apparent migration from densely populated banks to banks previously unoccupied (Table S3), suggesting that geographic range expansions may have also occurred. Shackell \& Frank (2003) documented the geographic range expansions of many prey and mesopredator species on the Scotian Shelf after the collapse of large predator populations. Further, Fisher \& Frank (2004) found that many of the species mentioned above exhibited strong positive correlations between abundance and area occupied, particularly following predator collapse. We found that increases in prey densities were strongly and positively correlated with the area-dependent increases in prey alpha diversity at both regime and annual time scales (Fig. 5a, Supplement 8). Increases in mesopredator densities and alpha diversity were, in contrast, only evident on larger banks (Brown's and Western; Supplement 8). This implies that different mechanisms governed the changes in SAR of these 2 trophic groups. For the mesopredator trophic group, increases in alpha diversity on the largest banks, which subsequently led to a strong SAR in the post1991 regime, resulted primarily from a migration of abundant core species from densely populated banks to previously unoccupied banks (Table S3). In contrast, core species in the prey trophic group evidently experienced increases in densities and consequent reductions in extinction risk as a consequence of reduced predation in the post-1992 period, but an examination of prey species identities in the pre-1992 and post-1991 regimes revealed that increases in species immigrations onto, and/or successful colonization of the banks also played a significant role in the steepening of the prey SAR in the post-collapse regime (Fig. 6). 
More than half (58\%) of the new prey species had not been reported on the Scotian Shelf prior to 1991 (i.e. were considered 'colonists,' Supplement 3). The southern and northern affinities of these species, and the increased correlation of prey community dissimilarities and geographic distance among banks (Fig. 7a) suggests that these new species immigrated from other regions and may well have successfully colonized the banks due to high productivity and low predation pressure. It is not possible to distinguish whether rates of immigration increased, or simply the frequency of successful colonization. It is possible that immigration of these species (i.e. attempted colonization) to the banks has occurred in the past (at what frequency is unknown), but successful colonization was only permitted when conditions became favorable (post-1991). It is also possible that some of these newly detected species were always present on the banks, but went undetected due to low abundances when predators were present. However, this argument is inconsistent with the reality that these immigrant/colonist species exhibited little to no increasing trend in abundance in the post-collapse regime (Supplement 9).

Given the limited pre- to post-collapse difference in average bottom temperature across the banks (Supplement 2), it does not appear that the immigrants/colonist species observed post-1992 were responding to long-term or local-scale temperature changes. Moreover, given that none of these smallbodied species has been commercially exploited (Supplement 3), their absence from the banks in the precollapse regime could not have been due to directed fishing. It is also possible that as a consequence of relaxed predation and lowered extinction rates post1991, successful prey immigration was facilitated by these immigrant species seeking refuge amongst other highly abundant groups as reported by Landeau \& Terborgh (1986) and Bakun \& Cury (1999). We conclude that reduced extinction rates and increased rates of immigration and/or colonization collectively led to the increased slopes of the prey SAR slope in the post-collapse regime, while range expansion and consequent decreases in extinction risk contributed to the strengthened mesopredator SAR.

Cazelles et al. (2016) recently called for the integration of a wider range of species interactions into the theory of island biogeography. Our findings, as detailed above, suggest that inclusion of the interaction between predator abundance and prey immigration/ colonization rates, and between predator abundance and mesopredator extinction rates, would be worthwhile additions to the evolving TTIB. Many researchers have theorized about how various types and strengths of species interactions, in combination with environmental drivers at different scales, may impact the scaling of diversity in ecological communities (Levins \& Culver 1971, Whittaker 2000, Calcagno et al. 2011). It is clear, however, that more empirical evidence directly related to the theory of island biogeography, and its modern extensions such as the TTIB, is required if these theories are to be effectively evaluated. This study provides the first empirical support for the extension of the TTIB to the scales of large marine ecosystems, provides insight into the inter-trophic level dynamics of ecosystem change, and contributes to a more integrative theory of island biogeography (Lomolino 2000, Cazelles et al. 2016).

Our findings also contribute support for the growing consensus that, despite global-scale declines in biodiversity (e.g. Butchart et al. 2010), diversity may actually increase at local scales in some regions in response to changing ecosystem states (Sax et al. 2002, Dornelas et al. 2014, Batt et al. 2017). While one goal of biodiversity conservation is to maintain ecosystem resilience, our analyses, among other revealing studies (e.g. Ellingsen et al. 2015), exposes that increased alpha diversity may, in itself, be an unreliable indicator of ecosystem health. Indeed, on the submarine banks of the Scotian Shelf, the pronounced increase in prey alpha diversity was a symptom of a disruptive 'trophic cascade' (Frank et al. 2005, Ellingsen et al. 2015). This finding is consistent with, and supportive of, the increased interest in the large fish indicator (Modica et al. 2014), functional diversity (Cadotte et al. 2011), and other ecosystem diagnostics, all of which signal a shift in the mindset of conservationists from a preoccupation with the protection of biodiversity to the protection of diversity of traits and the function of trophic webs.

Given the strong influence of body size on life history characteristics, including population stability in space and time (Roff 1992, Swain et al. 2007), it has been argued that such an increased dominance of small-bodied species would lead to ecosystem instability (Petrie et al. 2009). This reasoning is not inconsistent with the increased dependence of prey and mesopredator alpha diversity on bank area in the post-collapse regime (Fig. 4), and the increased occurrence of rare colonist species (Supplement 3), both of which suggest that these offshore bank communities have become more insular and possibly less temporally stable. It is also important to highlight that the post-1991 increase in prey alpha diversity does not discount the potential for a future decline in alpha diversity at all trophic levels and body sizes, 
and across species with all levels of colonization ability, if unsustainable levels of fishing at multiple trophic levels and/or habitat destruction were to continue unabated (the extinction debt hypothesis: Tilman et al. 1994, Duplisea et al. 2016).

Recognition of the importance of ecological theory in the development of management protocols and conservation science remains vital (e.g. Palmer et al. 1997). Our findings clearly indicate that habitat area plays an important role in determining the magnitude of the response of prey and mesopredator complexes to large predator depletion in marine ecosystems. Moreover, the changes in the SARs of prey and mesopredator complexes across semi-insular habitats clearly reflect shifts in the functional (body size) diversity of the larger community. These patterns will undoubtedly have implications for the future management of the Scotian Shelf ecosystem. Clearly, more work will be required to build a broader understanding of how species traits and interactions impact these patterns at various spatial scales (Ryberg \& Chase 2007, Stier et al. 2014), and in ecosystems with different predator roles (e.g. generalist versus specialists) and degrees of inter-specific competition.

In an ocean increasingly affected by human activities, where the disproportionate removal of predatory species continues to occur on a global scale (Worm 2015), it is imperative that we deepen our understanding of how large marine (and non-marine) ecosystems respond to perturbation. Given the insights gained from this study, island biogeography theory and its modern-day variants have the potential to provide the necessary framework for undertaking such analyses. In this connection, further exploration of the link between community-level responses to predator depletion and population-level dynamics is clearly required, as is an exploration of species colonization and extinction dynamics. This level of detail would contribute meaningfully to the evolution of TTIB, specifically as it pertains to large marine ecosystems.

Acknowledgements. We thank Dr. Thierry Boulinier for advice concerning species detectability issues and species richness estimators, and Dr. Jonathan Fisher, Dr. Brian Petrie, and Kiyomi French for their constructive and insightful reviews. We also thank Dr. Nigel Yoccoz, Dr. Torkild Tveraa, Dr. Kari Ellingsen, Dr. Shelley Arnott, Dr. Bob Montgomerie, and Dr. Ryan Danby for helpful advice in both early and late stages of this project. We thank Fisheries and Oceans Canada, Queen's University, the Natural Sciences and Engineering Research Council (Canada), and the Norwegian Institute for Nature Research DRIVEBANKS project (https://www.nina.no/english/Fields-of-research/Projects/ Drivebanks) for the funding that made this research possible.

\section{LITERATURE CITED}

Bakun A, Cury P (1999) The 'school trap': a mechanism promoting large-amplitude out-of-phase population oscillations of small pelagic fish species. Ecol Lett 2:349-351

* Batt RD, Morley JW, Selden RL, Tingley MW, Pinsky ML (2017) Gradual changes in range size accompany long term trends in species richness. Ecol Lett 20:1148-1157

Baum JK, Worm B (2009) Cascading top down effects of changing oceanic predator abundances. J Anim Ecol 78: 699-714

* Bax N, Williamson A, Aguero M, Gonzalez E, Geeves W (2003) Marine invasive alien species: a threat to global biodiversity. Mar Policy 27:313-323

*Boyce DG, Frank KT, Worm B, Leggett WC (2015) Spatial patterns and predictors of trophic control in marine ecosystems. Ecol Lett 18:1001-1011

Bundy A, Heymans JJ, Morisette L, Savenkoff C (2009) Seals, cod and forage fish: a comparative exploration of variations in the theme of stock collapse and ecosystem change in four Northwest Atlantic ecosystems. Prog Oceanogr 81:188-206

Butchart SH, Walpole M, Collen B, Van Strien A and others (2010) Global biodiversity: indicators of recent declines. Science 328:1164-1168

Cadotte MW, Carscadden K, Mirotchnick N (2011) Beyond species: functional diversity and the maintenance of ecological processes and services. J Appl Ecol 48:1079-1087

Calcagno V, Massol F, Mouquet N, Jarne P, David P (2011) Constraints on food chain length arising from regional metacommunity dynamics. Proc R Soc B 278:3042-3049

Cazelles K, Mouquet N, Mouillot D, Gravel D (2016) On the integration of biotic interaction and environmental constraints at the biogeographical scale. Ecography 39: 921-931

Chase JM, Biro EG, Ryberg WA, Smith KG (2009) Predators temper the relative importance of stochastic processes in the assembly of prey metacommunities. Ecol Lett 12: 1210-1218

* Cheung WWL, Lam VW, Sarmiento JL, Kearney K, Watson R, Pauly D (2009) Projecting global marine biodiversity impacts under climate change scenarios. Fish Fish 10: 235-251

Choi JS, Frank KT, Petrie BD, Leggett WC (2005) Integrated assessment of a large marine ecosystem: a case study of the devolution of the eastern Scotian Shelf, Canada. Oceanogr Mar Biol Annu Rev 43:47-67

Cong L, Sheng J, Thompson KT (1996) A retrospective study of the particle retention on the outer banks of the Scotian Shelf, 1956-1993. Can Tech Rep Hydrogr Ocean Sci 170

Connor EF, McCoy ED (1979) The statistics and biology of the species-area relationship. Am Nat 113:791-833

Costa GC (2009) Predator size, prey size, and dietary niche breadth relationships in marine predators. Ecology 90: 2014-2019

* Crooks KR, Soulé ME (1999) Mesopredator release and avifaunal extinctions in a fragmented system. Nature 400: 563-566

Dengler J (2009) Which function describes the species-area relationship best? A review and empirical evaluation. J Biogeogr 36:728-744

DFO (Fisheries and Oceans Canada) (2016) 2015 Maritimes research vessel survey trends on the Scotian Shelf and Bay of Fundy. DFO Canadian Science Advisory Secretariat Science Response 2016/011. DFO, Ottawa 
Dormann CF, Elith J, Bacher S, Buchmann C and others (2013) Collinearity: a review of methods to deal with it and a simulation study evaluating their performance. Ecography 36:27-46

Dornelas M, Gotelli NJ, McGill B, Shimadzu H, Moyes F, Sievers C, Magurran AE (2014) Assemblage time series reveal biodiversity change but not systematic loss. Science 344:296-299

Doubleday WG, Rivard D (1981) Bottom trawl surveys. Publ Spec Can Sci Halieut Aquat 47:385-394

Drakare S, Lennon JJ, Hillebrand H (2006) The imprint of the geographical, evolutionary and ecological context on species-area relationships. Ecol Lett 9:215-227

Dulvy NK, Ellis JR, Goodwin NB, Grant A, Reynolds JD, Jennings S (2004) Methods of assessing extinction risk in marine fishes. Fish Fish 5:255-276

Duplisea DE, Frisk MG, Trenkel VM (2016) Extinction debt and colonizer credit on a habitat perturbed fishing bank. PLOS ONE 11:e0166409

Ellingsen KE, Anderson MJ, Shackell NL, Tveraa T, Yoccoz NG, Frank KT (2015) The role of a dominant predator in shaping biodiversity over space and time in a marine ecosystem. J Anim Ecol 84:1242-1252

Fisher JAD, Frank KT (2004) Abundance-distribution relationships and conservation of exploited marine fishes. Mar Ecol Prog Ser 279:201-213

Frank KT (1992) Demographic consequences of age-specific dispersal in marine fish populations. Can J Fish Aquat Sci 49:2222-2231

Frank KT, Brickman D (2000) Allee effects and compensatory population dynamics within a stock complex. Can J Fish Aquat Sci 57:513-517

Frank KT, Shackell NL (2001) Area-dependent patterns of finfish diversity in a large marine ecosystem. Can J Fish Aquat Sci 58:1703-1707

Frank KT, Petrie B, Choi JS, Leggett WC (2005) Trophic cascades in a formerly cod-dominated ecosystem. Science 308:1621-1623

Frank KT, Petrie B, Fisher JAD, Leggett WC (2011) Transient dynamics of an altered large marine ecosystem. Nature 477:86-89

Frank KT, Leggett WC, Petrie BD, Fisher JA, Shackell NL, Taggart CT (2013) Irruptive prey dynamics following the groundfish collapse in the Northwest Atlantic: an illusion? ICES J Mar Sci 70:1299-1307

* Gleason HA (1922) On the relation between species and area. Ecology 3:158-162

Graham MH (2003) Confronting multicollinearity in ecological multiple regression. Ecology 84:2809-2815

Holt RD (2009) Towards a trophic island biogeography: reflections on the interface of island biogeography and food web ecology. In: Losos JB, Ricklefs RE (eds) The theory of island biogeography revisited. Princeton University Press, Princeton, NJ, p 143-185

Hutchings JA, Reynolds JD (2004) Marine fish population collapses: consequences for recovery and extinction risk. AIBS Bull 54:297-309

Jacquet C, Mouillot D, Kulbicki M, Gravel D (2017) Extensions of island biogeography theory predict the scaling of functional trait composition with habitat area and isolation. Ecol Lett 20:135-146

Johnston NK, Pu Z, Jiang L (2016) Predator identity influences metacommunity assembly. J Anim Ecol 85:1161-1170

Juan-Jordá MJ, Mosqueira I, Cooper AB, Freire J, Dulvy NK (2011) Global population trajectories of tunas and their relatives. Proc Natl Acad Sci USA 108:20650-20655

* Landeau L, Terborgh J (1986) Oddity and the 'confusion effect' in predation. Anim Behav 34:1372-1380

* Levins R, Culver D (1971) Regional coexistence of species and competition between rare species. Proc Natl Acad Sci USA 68:1246-1248

Link JS, Almeida FP (2000) An overview and history of the food web dynamics program of the Northeast Fisheries Science Center, Woods Hole, Massachusetts. US Department of Commerce, National Oceanic and Atmospheric Administration, National Marine Fisheries Service, Northeast Region, Northeast Fisheries Science Center, Woods Hole, MA

* Loder JW, Ross CK, Smith PC (1988) A space- and timescale characterization of circulation and mixing over submarine banks, with application to the northwestern Atlantic continental shelf. Can J Fish Aquat Sci 45: 1860-1885

Komolino M (2000) A call for a new paradigm of island biogeography. Glob Ecol Biogeogr 9:1-6

MacArthur RH, Wilson EO (1967) The theory of island biography. Princeton University Press, Princeton, NJ

Mazerolle MJ (2016) AICcmodavg: Model selection and multimodel inference based on (Q)AIC(c). R package version 2.1-0. https://cran.r-project.org/package=AICcmodavg

*Modica L, Velasco F, Preciado I, Soto M, Greenstreet SP (2014) Development of the large fish indicator and associated target for a Northeast Atlantic fish community. ICES J Mar Sci 71:2403-2415

\% Oksanen J, Blanchet FG, Friendly M, Kindt DT and others (2017) Vegan: community ecology package. R package version 2.4-2. https://CRAN.R-project.org/package=vegan

* Olden JD, Hogan ZS, Zanden MJV (2007) Small fish, big fish, red fish, blue fish: size-biased extinction risk of the world's freshwater and marine fishes. Glob Ecol Biogeogr 16:694-701

Paine RT (1966) Food web complexity and species diversity. Am Nat 100:65-75

*Palmer MA, Ambrose RF, Poff NL (1997) Ecological theory and community restoration ecology. Restor Ecol 5: 291-300

* Petrie B, Frank KT, Shackell NL, Leggett WC (2009) Structure and stability in exploited marine fish communities: quantifying critical transitions. Fish Oceanogr 18:83-101

* Prugh LR, Stoner CJ, Epps CW, Bean WT, Ripple WJ, Laliberte AS, Brashares JS (2009) The rise of the mesopredator. Bioscience 59:779-791

R Core Team (2017) R: a language and environment for statistical computing. R Foundation for Statistical Computing, Vienna

Reynolds JD, Dulvy NK, Goodwin NB, Hutchings JA (2005) Biology of extinction risk in marine fishes. Proc R Soc B 272:2337-2344

Ricard D, Shackell NL (2013) Population status (abundance/biomass, geographic extent, body size and condition), important habitat, depth, temperature and salinity of marine fish and invertebrates on the Scotian Shelf and Bay of Fundy (1970-2012). Can Tech Rep Fish Aquat Sci 3012

Roff DA (1992) The evolution of life histories: theory and analysis. Chapman \& Hall, London

* Romanuk TN, Hayward A, Hutchings JA (2011) Trophic level scales positively with body size in fishes. Glob Ecol Biogeogr 20:231-240 
Ryberg WA, Chase JM (2007) Predator-dependent speciesarea relationships. Am Nat 170:636-642

Ryberg WA, Smith KG, Chase JM (2012) Predators alter the scaling of diversity in prey metacommunities. Oikos 121: 1995-2000

Sax DF, Gaines SD, Brown JH (2002) Species invasions exceed extinctions on islands worldwide: a comparative study of plants and birds. Am Nat 160:766-783

Shackell NL, Frank KT (2000) Larval fish diversity on the Scotian Shelf. Can J Fish Aquat Sci 57:1747-1760

Shackell NL, Frank KT (2007) Compensation in exploited marine fish communities on the Scotian Shelf, Canada. Mar Ecol Prog Ser 336:235-247

Shackell NL, Frank KT, Fisher JA, Petrie B, Leggett WC (2010) Decline in top predator body size and changing climate alter trophic structure in an oceanic ecosystem. Proc R Soc B 277:1353-1360

Shackell NL, Fisher JA, Frank KT, Lawton P (2012) Spatial scale of similarity as an indicator of metacommunity stability in exploited marine systems. Ecol Appl 22: 336-348

Scharf FS, Juanes F, Rountree RA (2000) Predator size-prey size relationships of marine fish predators: interspecific

Editorial responsibility: Jake Rice,

Ottawa, Ontario, Canada variation and effects of ontogeny and body size on trophic-niche breadth. Mar Ecol Prog Ser 208:229-248

Shephard S, Reid DG, Greenstreet SP (2011) Interpreting the large fish indicator for the Celtic Sea. ICES J Mar Sci 68:1963-1972

Smith EP, van Belle G (1984) Nonparametric estimation of species richness. Biometrics 40:119-129

* Stier AC, Hanson KM, Holbrook SJ, Schmitt RJ, Brooks AJ (2014) Predation and landscape characteristics independently affect reef fish community organization. Ecology 95:1294-1307

* Swain DP, Sinclair AF, Hanson JM (2007) Evolutionary response to size-selective mortality in an exploited fish population. Proc R Soc B 274:1015-1022

*Tilman D, May RM, Lehman CL, Nowak MA (1994) Habitat destruction and the extinction debt. Nature 371:65-66

*Whittaker RJ (2000) Scale, succession and complexity in island biogeography: Are we asking the right questions? Glob Ecol Biogeogr 9:75-85

*Worm B (2015) A most unusual (super) predator. Science 349:784-785

Whorm B, Hilborn R, Baum JK, Branch TA and others (2009) Rebuilding global fisheries. Science 325:578-585

Submitted: May 31, 2018; Accepted: October 25, 2018

Proofs received from author(s): November 30, 2018 